\title{
Role of Intrinsic Conductances Underlying Responses to Transients in Octopus Cells of the Cochlear Nucleus
}

\author{
Nace L. Golding, Michael J. Ferragamo, and Donata Oertel \\ Department of Physiology, University of Wisconsin, Madison, Wisconsin 53706
}

Recognition of acoustic patterns in natural sounds depends on the transmission of temporal information. Octopus cells of the mammalian ventral cochlear nucleus form a pathway that encodes the timing of firing of groups of auditory nerve fibers with exceptional precision. Whole-cell patch recordings from octopus cells were used to examine how the brevity and precision of firing are shaped by intrinsic conductances. Octopus cells responded to steps of current with small, rapid voltage changes. Input resistances and membrane time constants averaged 2.4 $\mathrm{M} \Omega$ and $210 \mu \mathrm{sec}$, respectively $(n=15)$. As a result of the low input resistances of octopus cells, action potential initiation required currents of at least $2 \mathrm{nA}$ for their generation and never occurred repetitively. Backpropagated action potentials recorded at the soma were small $(10-30 \mathrm{mV})$, brief $(0.24-0.54$ $\mathrm{msec}$ ), and tetrodotoxin-sensitive. The low input resistance arose in part from an inwardly rectifying mixed cationic con- ductance blocked by cesium and potassium conductances blocked by 4-aminopyridine (4-AP). Conductances blocked by 4-AP also contributed to the repolarization of the action potentials and suppressed the generation of calcium spikes.

In the face of the high membrane conductance of octopus cells, sodium and calcium conductances amplified depolarizations produced by intracellular current injection over a time course similar to that of EPSPs. We suggest that this transient amplification works in concert with the shunting influence of potassium and mixed cationic conductances to enhance the encoding of the onset of synchronous auditory nerve fiber activity.

Key words: cochlear nucleus; auditory pathways; octopus cells; potassium channels; inward rectifier; $\mathrm{I}_{\mathrm{h}}$; 4-aminopyridine; cesium
Recognition of acoustic patterns underlies the ability of animals to use sound to interpret events in the environment and to understand communication sounds. Early electrophysiological studies of the auditory system revealed that auditory nerve fibers discharge during a restricted phase of low-frequency periodic stimuli (Galambos and Davis, 1943; Rose et al., 1967), supporting the hypothesis that the spectral content of low-frequency sound could be encoded in the temporal firing patterns of auditory neurons. Indeed, the interspike intervals of auditory nerve fiber discharges appear to provide information required for the accurate determination of the pitch of a variety of simple and complex sounds (Cariani and Delgutte, 1996a,b; Yost et al., 1996). Synchronicity in the discharges of auditory nerve fibers also signals salient features present in whispered and normal speech (Young and Sachs, 1979; Voigt et al., 1982; Stevens and Wickesberg, 1999).

Octopus cells in the cochlear nuclei detect biologically relevant patterns encoded in the coincident firing of populations of auditory nerve fibers (Rhode, 1998). Octopus cells respond strongly to transient and periodic broadband sounds. Both tones and noise evoke "onset" responses in vivo, consisting of a single precisely timed action potential followed by little or no subsequent activity

Received Aug. 13, 1998; revised Jan. 29, 1999; accepted Feb. 1, 1999.

This work was supported by National Institutes of Health Grant DC 00176 (to D.O.). We are grateful to Jo Ann Ekleberry, Inge Siggelkow, and Joan Meister for making many liters of solutions and for flawless histological processing. We thank Ramazan Bal for contributing data from stellate cells. We also thank our colleagues in the Department of Physiology, who continue to contribute to our work in important ways.

Correspondence should be addressed to Dr. Nace Golding, Department of Physiology and Neurobiology, Northwestern University, 2153 North Campus Drive, Evanston, IL 60208.

Copyright (C) 1999 Society for Neuroscience $\quad 0270-6474 / 99 / 192897-09 \$ 05.00 / 0$
(Godfrey et al., 1975; Rhode et al., 1983; Rhode and Smith, 1986; Friauf and Ostwald, 1988; Smith et al., 1993; Feng et al., 1994). Octopus cells may entrain to click trains and tones at frequencies of up to $1 \mathrm{kHz}$ (Rhode and Smith, 1986; Smith et al., 1993). In addition, octopus cells show the most robust synchronization to the envelope of amplitude-modulated signals of all the major cell types in the cochlear nuclei (Rhode, 1994).

The octopus cells occupy a discrete teardrop-shaped area in the dorsocaudal posteroventral cochlear nucleus (PVCN). Forming one of the four ascending pathways from the ventral cochlear nucleus, their large axons project to the superior paraolivary nucleus, mainly contralaterally (Schofield, 1995), and to the contralateral ventral nucleus of the lateral lemniscus (Smith et al., 1993; Adams, 1997; Schofield and Cant, 1997; Vater et al., 1997) (for review, see Oertel, 1999).

A previous study of octopus cells using intracellular microelectrode recordings showed that EPSPs arising from auditory nerve fibers are extremely rapid ( $\sim 1-2 \mathrm{msec}$ in duration) and are mediated primarily by AMPA-type glutamate receptors (Golding et al., 1995). The same study showed that the temporal fidelity of this rapid excitation was maintained in part by an unusually high resting conductance. In the present study, we have confirmed and extended these findings by using whole-cell patch recordings, which obviate several limitations of high-resistance sharp microelectrodes, including an impalement-associated shunt and severe constraints on the speed and magnitude of current that can be injected into the cell. We show that the precise, transient firing pattern that is the hallmark of octopus cells arises from the coordinated action of sodium and calcium conductances, which amplify the onset of depolarizations, and of potassium and mixed cationic conductances, which maintain the depolarizations' brevity. 


\section{MATERIALS AND METHODS}

Preparation and maintenance of slices. Coronal brainstem slices containing the posterior cochlear nucleus were prepared from mice (CBA, ICR, or B5 strains) of ages between 18 and 26 postnatal days. Mice were decapitated, and the brains were dissected in external saline at $31^{\circ} \mathrm{C}$. External saline contained (in $\mathrm{mm}$ ): $130 \mathrm{NaCl}, 3 \mathrm{KCl}, 1.3 \mathrm{MgSO}_{4}, 2.4$ $\mathrm{CaCl}_{2}, 20 \mathrm{NaHCO}_{3}, 3 \mathrm{HEPES}, 10$ glucose, and $1.2 \mathrm{KH}_{2} \mathrm{PO}_{4}, \mathrm{pH} 7.4$. Then the brain was blocked coronally at the posterior edge of the cerebellum and anteriorly between the inferior and superior colliculi. The rostral surface of the brain was glued to a Teflon block, and one to two slices, $200 \mu \mathrm{m}$ thick, were made of the most posterior pole of the cochlear nucleus with an oscillating tissue slicer (Frederick Haer, New Brunswick, ME). Slices were allowed to recover for at least $1 \mathrm{hr}$ submerged in a holding chamber containing oxygenated external saline at $33^{\circ} \mathrm{C}$. Slices then were transferred to a recording chamber that was superfused continuously with oxygenated external saline at $\sim 8 \mathrm{ml} / \mathrm{min}$.

Electrophysiology. Putative octopus cells were visualized directly with a $63 \times$ water immersion lens in conjunction with differential interference contrast (Nomarski) optics. Whole-cell patch recordings were made with standard techniques.

Electrophysiological data were recorded with an Axopatch 200A amplifier in "fast" current-clamp mode and transferred to computer via a Digidata 1200 interface (Axon Instruments, Foster City, CA). Stimulus generation and data acquisition were performed with pClamp software (version 6.0; Axon Instruments). Voltages were low-pass-filtered at 5-10 $\mathrm{kHz}$ and sampled digitally at $40-80 \mathrm{kHz}$.

Pipettes were pulled from borosilicate glass (1.2 $\mathrm{mm}$ outer diameter), and the tips were heat-polished on a microforge. The internal pipette solution in most experiments consisted of (in mM): $140 \mathrm{~K}$-gluconate, 5 $\mathrm{NaCl}, 1 \mathrm{MgSO}_{4}, 1 \mathrm{CaCl}_{2}, 11$ EGTA, and $10 \mathrm{HEPES}, \mathrm{pH}$ 7.25. In some experiments Cs-gluconate $(140 \mathrm{~mm})$ was substituted for K-gluconate. All traces have been corrected for a junction potential of 12 and $10 \mathrm{mV}$ for $\mathrm{K}$-gluconate and Cs-gluconate internal solutions, respectively.

Pharmacological agents were dissolved in external saline and were bath-applied. Cesium chloride $(\mathrm{CsCl})$, 4-aminopyridine (4-AP), and tetrodotoxin (TTX) were obtained from Sigma (St. Louis, MO). In external solutions containing $15 \mathrm{~mm} \mathrm{CsCl}$, $\mathrm{CsCl}$ was substituted for $\mathrm{NaCl}$ in equimolar concentrations to prevent gross changes in osmolarity. In external solutions with no added calcium (nominally calcium-free), magnesium was substituted in equimolar concentrations for calcium. When the external concentration of sodium was reduced from 130 to 20 $\mathrm{mM}$, sodium was substituted with choline $\left(\mathrm{Cl}^{-}\right.$salt $)$, a molecule impermeant to voltage-gated ion channels.

Responses to injected currents of up to $5 \mathrm{nA}$ were corrected off-line for the voltage drop across the series resistance of the recording electrodes $(<19 \mathrm{M} \Omega)$. Over this range of series resistances the time constant of the current-clamp amplifier was $\sim 10$ times faster than that of the cell membrane, allowing voltage contributions arising from series resistance to be resolved adequately from those of the cell membrane. The adequacy of series resistance corrections was assessed by eye for every trace, and a given series resistance determination was accepted only if it accurately described responses to a series of positive and negative current pulses of at least five different amplitudes.

Measurements of the apparent membrane time constant were made by fitting a single exponential waveform to small hyperpolarizations evoked by current pulses. Outside of this limited voltage range, responses appeared more complex and exhibited multiple exponential components. Even close to rest, responses typically displayed a small depolarizing sag. In such cases, responses were fit from near the start of the response to the maximum of the hyperpolarization. The presence of active conductances in the physiological voltage range also complicated measurements of input resistance, particularly in the presence of channel blockers. To facilitate comparison across different experimental conditions, we assessed the input resistance of cells within $5 \mathrm{mV}$ negative to the resting potential. Values of action potential duration reflect measurements made at their bases.

Histology. All octopus cells were identified morphologically via the internal dialysis of the cell with a pipette solution that included $0.1 \%$ biocytin (Sigma). In some experiments, $\mathrm{T}$ stellate cells bordering the octopus cell area were labeled. Their morphology and physiology were distinguished easily from those of octopus cells and were remarkably consistent with previous studies in slices in which sharp microelectrodes were used (Wu and Oertel, 1987; Oertel et al., 1990). Slices were fixed in $4 \%$ paraformaldehyde and stored at $4^{\circ} \mathrm{C}$ for up to 3 weeks. Biocytin-filled cells were visualized with the avidin-biotinylated horseradish peroxidase

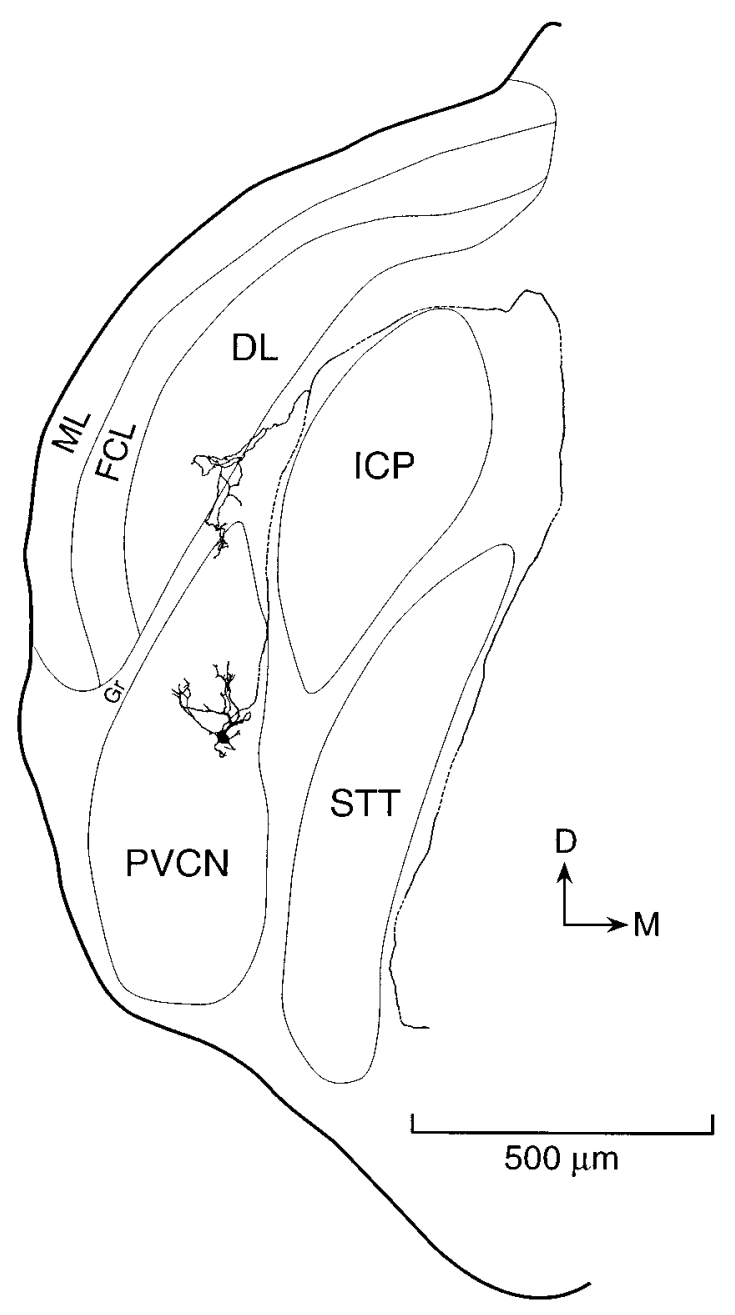

Figure 1. Morphology of an octopus cell labeled by intracellular perfusion with biocytin and reconstructed with a camera lucida from a series of sections cut in the same coronal plane as the original slice. A labeled octopus cell is located in the most caudal and dorsal part of the posteroventral cochlear nucleus $(P V C N)$. The recording was made from the cell body near the caudal surface of the slice. The dendrites of the cell extend anteriorly through the thickness of the slice. Its axon exits through a fiber tract that lies at the medial surface of the dorsal cochlear nucleus and goes around the inferior cerebellar peduncle $(I C P)$ and spinal trigeminal tract $(S T T)$. A collateral innervates granule cell regions $(G r)$ that lie adjacent to the octopus cell area. The molecular layer $(M L)$, fusiform cell layer $(F C L)$, and deep layer $(D L)$ of the dorsal cochlear nucleus overlie the PVCN.

complex reaction (Vectastain ABC Elite Kit; Vector Laboratories, Burlingame, CA), using nickel/cobalt-intensified DAB as a chromogen. Then slices were resectioned at $60 \mu \mathrm{m}$, mounted on coated slides, and counterstained with cresyl violet to view the orientation of labeled cells with respect to the cytoarchitectural boundaries of the cochlear nucleus.

\section{RESULTS}

In coronal slices the cell bodies of octopus cells resided in a wedge-shaped region of the caudalmost PVCN just medial to the dorsal cochlear nucleus (Fig. 1). The present results are based on a series of 43 patch-clamp recordings of anatomically identified octopus cells; most of the data described in the present study are from 29 of those recordings. The morphology of the labeled octopus cells in the present study resembled that described previously in murine slices (Golding et al., 1995). Octopus cells include a large cell body of $\sim 25 \mu \mathrm{m}$ diameter. Their thick 
A
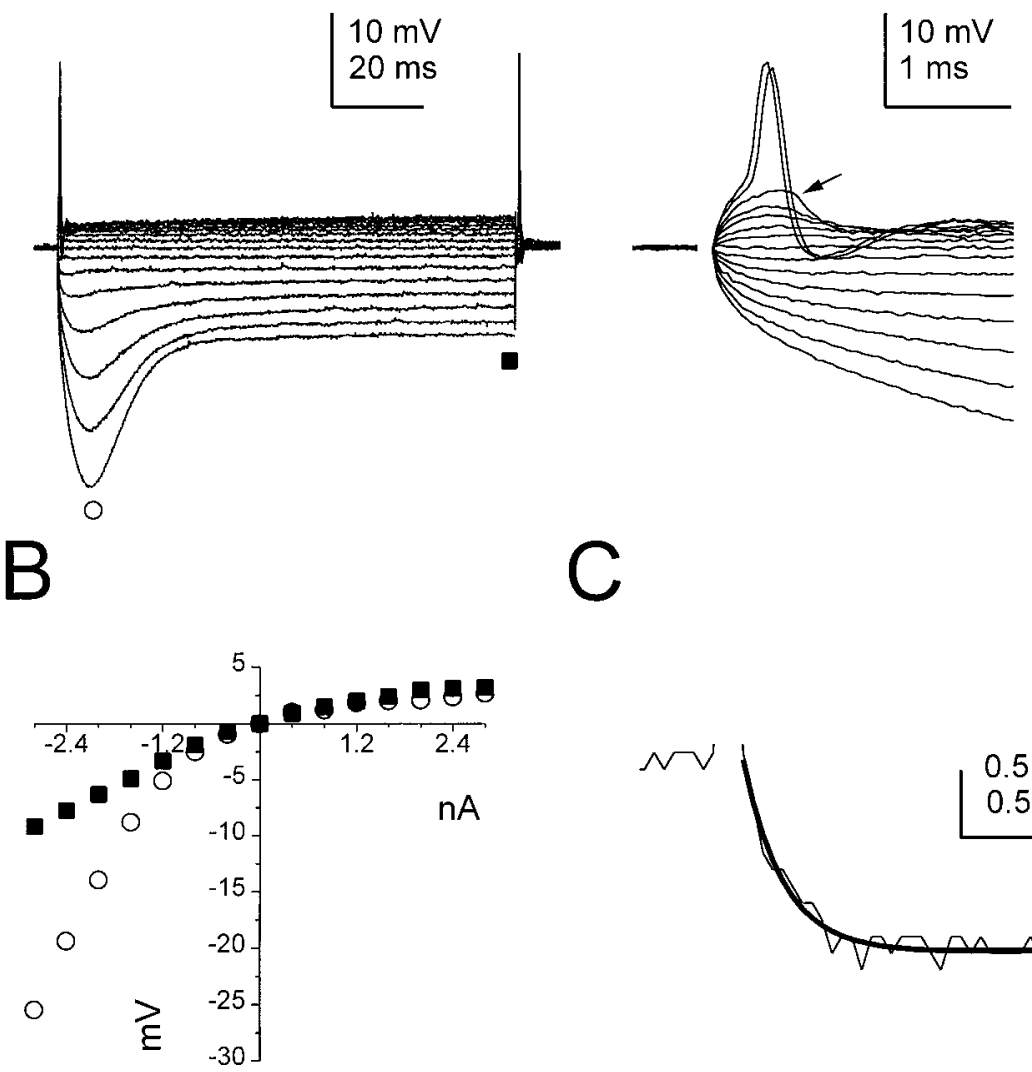

Figure 2. Electrophysiological properties of octopus cells. A, Left, Responses of an octopus cell to steps of current between 2.8 and $-2.8 \mathrm{nA}$ in $0.4 \mathrm{nA}$ increments. Responses to depolarizing current pulses are characterized by strong outward rectification. Inward rectification is visible in responses to hyperpolarizing current pulses as a delayed depolarizing sag. A, Right, Action potentials were small $(14 \mathrm{mV})$ and narrow $(0.3 \mathrm{msec}$ base width) and could be evoked at the onset and offset of the large depolarizing and hyperpolarizing current pulses, respectively. Subthreshold responses to depolarizing current show a prominent "hump" at their onset (e.g., arrow). $B$, The voltage-current relationship of the same cell measured at the peak and steady-state of the responses shown in $A$ (circles and squares, respectively). The steady-state input resistance within $-5 \mathrm{mV}$ of rest was $2.4 \mathrm{M} \Omega$. $C$, The membrane time constant of the cell shown in $A$, measured from a $1.4 \mathrm{mV}$ hyperpolarizing pulse, was described by a single exponential function (dark trace) and was $0.16 \mathrm{msec}$. dendrites tend to emanate from the rostral pole of the soma. Parasagittal views in previous studies showed that in every case the cell bodies lay posteriorly and that the dendrites spread across the tonotopic array of auditory nerve fibers (Oertel et al., 1990; Golding et al., 1995). Cells consistently were oriented with the cell body residing on the lowest frequency side of the tonotopic array, with their dendrites emanating toward the high frequency side. In the coronal slices of the present study, slices were oriented so that the cell bodies were accessible from the upper, caudal surface of the slice and the dendrites spread through its thickness (Fig. 1). This approach avoided damaging the dendrites of the cells and in many cases, such as that shown in Figure 1, preserved long parts of the axon. In most cells the axon was preserved in the slice for several hundred microns.

Although the resting potentials of octopus cells were conventional ( $-63 \pm 3 \mathrm{mV} ; n=43)$, other intrinsic membrane properties were distinctive (Fig. 2). Responses to hyperpolarizing current pulses exhibited a delayed depolarizing sag (inward rectification) that reached a steady-state level 20-30 msec after the onset of the stimulus. Outward rectification was marked in responses to depolarizing current pulses. The slope of the steadystate voltage-current $(V-I)$ relationship near rest was $2.4 \pm 0.9$ $\mathrm{M} \Omega(n=15$; Fig. $2 B)$. The apparent membrane time constant of octopus cells for hyperpolarizing responses within $5 \mathrm{mV}$ of rest averaged $0.21 \pm 0.06 \mathrm{msec}$ (Fig. $2 C$ ). Subthreshold responses to depolarizing currents showed rapid depolarizing voltage transients, or humps, that were graded in amplitude with current strength (Fig. $2 A$, right traces). At a discrete threshold these depolarizing humps led to the generation of a small and brief action potential $(15.5 \pm 6.9 \mathrm{mV}$ and $0.3 \pm 0.1 \mathrm{msec}$, respectively; $n=12$ ). Repetitive firing was never observed in response to current pulses as large as $5 \mathrm{nA}$.

The electrophysiological properties of octopus cells stood in stark contrast to those of $\mathrm{T}$ stellate cells that surrounded the octopus cell area in the VCN, which exhibited input resistances of $148 \pm 49 \mathrm{mV}$ and apparent membrane time constants of $7.1 \pm 2.1$ msec $(n=11)$. In response to depolarizing current, T stellate cells fired trains of action potentials that averaged $78 \pm 5 \mathrm{mV}$ in amplitude $(n=11)$. These results indicate that the unusual electrophysiological properties of octopus cells did not result from a pathological condition of the slice preparation.

Despite their unusual small size and rapid time course, action potentials in octopus cells were blocked by TTX (Fig. $3 A$ ) and are thus pharmacologically identical to sodium-dependent spikes described in other cells in the nervous system. The amplitude of action potentials recorded at the cell body was dependent on the initial slope of the membrane depolarizations giving rise to them (Fig. 3B,C). The amplitude of spikes increased linearly with corresponding increases in the initial slope before saturation (Fig. $3 C$ ). The sensitivity of the amplitude of action potentials to the initial slope of depolarizations could reflect a more synchronous activation of sodium channels, which would result in a larger inward current underlying the action potential. No relationship was observed between the length of preserved axon and the amplitude of action potentials.

Voltage-gated sodium channels also contributed to the peaks of subthreshold responses at the onset of depolarizing current pulses injected through the somatic recording electrode $(n=5)$. Superimposed in each panel in Figure $4 A$ are the initial responses of an octopus cell to a 0.9 and $1.9 \mathrm{nA}$ current pulse in various pharma- 

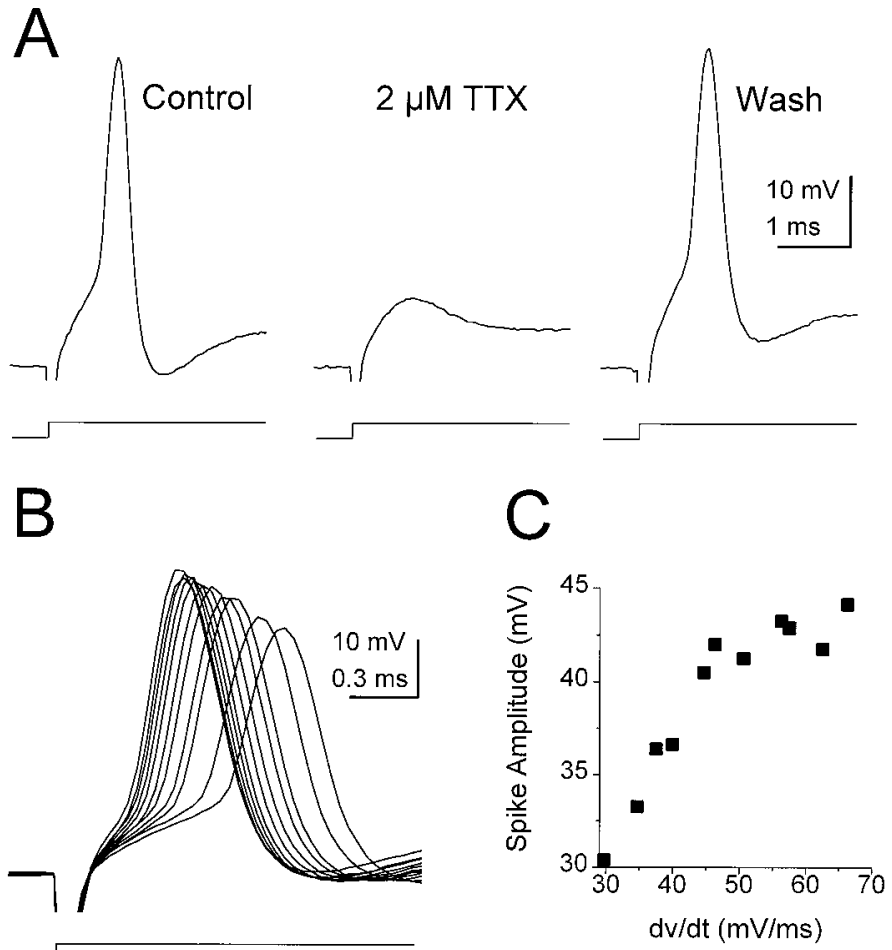

Figure 3. Action potentials in octopus cells. $A$, A large depolarizing current step evoked a small spike in an octopus cell that was blocked reversibly by $2 \mu \mathrm{M}$ TTX. Current steps in Control and in $2 \mu M$ TTX were $2.0 \mathrm{nA}$; in Wash it was $2.4 \mathrm{nA}$. B, The amplitude of action potentials increased with the size of depolarizing current steps. $C$, Plot of spike amplitude versus the rate of change of the initial $120 \mu \mathrm{sec}$ of the response shows that spike amplitude increased approximately linearly with the rate of change of voltage before saturation.

cological conditions (responses to $2 \mathrm{nA}$ current pulses elicited single action potentials). In this experiment the peak of the response to the $1.9 \mathrm{nA}$ current pulse in normal saline (control) was attenuated by $\sim 2 \mathrm{mV}$ in the presence of TTX, indicating that sodium channels amplified the initial voltage transient. The smaller response was unaffected in large part, however. In the presence of a solution containing TTX with no added calcium (a nominally 0 calcium solution), the peak of the response to the 1.9 $\mathrm{nA}$ current pulse was attenuated further by $\sim 1 \mathrm{mV}$, indicating that a low-threshold calcium conductance also contributed to the initial peak depolarization. Figure $4 B$ shows the amplitude of the peak of the initial depolarizing response in the control, TTX, and TTX/0 calcium conditions for current steps covering the subthreshold voltage range. The amplification of voltage responses by sodium channels is reflected in the upward inflection in the peak responses $>8 \mathrm{mV}$ in control solution (squares), whereas amplification by calcium channels is apparent above $5 \mathrm{mV}$ (circles). The concerted action of both sodium and calcium channels reduced the current necessary to reach the largest subthreshold responses by over $1 \mathrm{nA},>33 \%$ less current than that required to reach a comparable membrane potential in the absence of any contribution from these channels. Whereas sodium channels consistently amplified depolarizing transients in all five cells that were examined, amplification by calcium channels was detected in only one of the five cells, reflecting either variability in the number or types of calcium channels expressed in octopus cells and/or differences in the spatial location of the channels in the cell. Significantly, the time course of the initial voltage transients evoked by current injection through the somatic recording electrode was brief, $\sim 1-2$ msec, which corresponds well to the time course of EPSPs evoked from auditory nerve stimulation in octopus cells (Golding et al., 1995). Thus it is likely that voltage-gated sodium and calcium currents amplify excitatory synaptic input both in vitro and in vivo.

Large currents are required to reach the threshold for action potential initiation. The need for large currents is a consequence of the high membrane conductance of octopus cells and is counteracted only partially by the amplifying effects of sodium and calcium conductances. Several lines of evidence indicate that a contribution arises from an inwardly rectifying mixed cationic conductance. Extracellular cesium (15 mM), which blocks inwardly rectifying conductances, hyperpolarized the resting potential $(-62.3 \pm 1.7 \mathrm{mV})$ by $5.5 \pm 1.5 \mathrm{mV}(n=8)$ and blocked the delayed depolarizing sag in responses to hyperpolarizing current (Fig. $5 A$ ). In some cells, such as the example shown in Figure $5 A$, the depolarizing sag in weaker hyperpolarizing responses was blocked only partially by cesium, possibly reflecting the known voltage-dependent block of cesium on inwardly rectifying channels (Hagiwara et al., 1976). Most significantly, however, cesium increased the input resistance within $5 \mathrm{mV}$ of rest from $2.9 \pm 1.0$ to $17.9 \pm 9.3 \mathrm{M} \Omega(n=5)$ and increased the membrane time

\section{A}
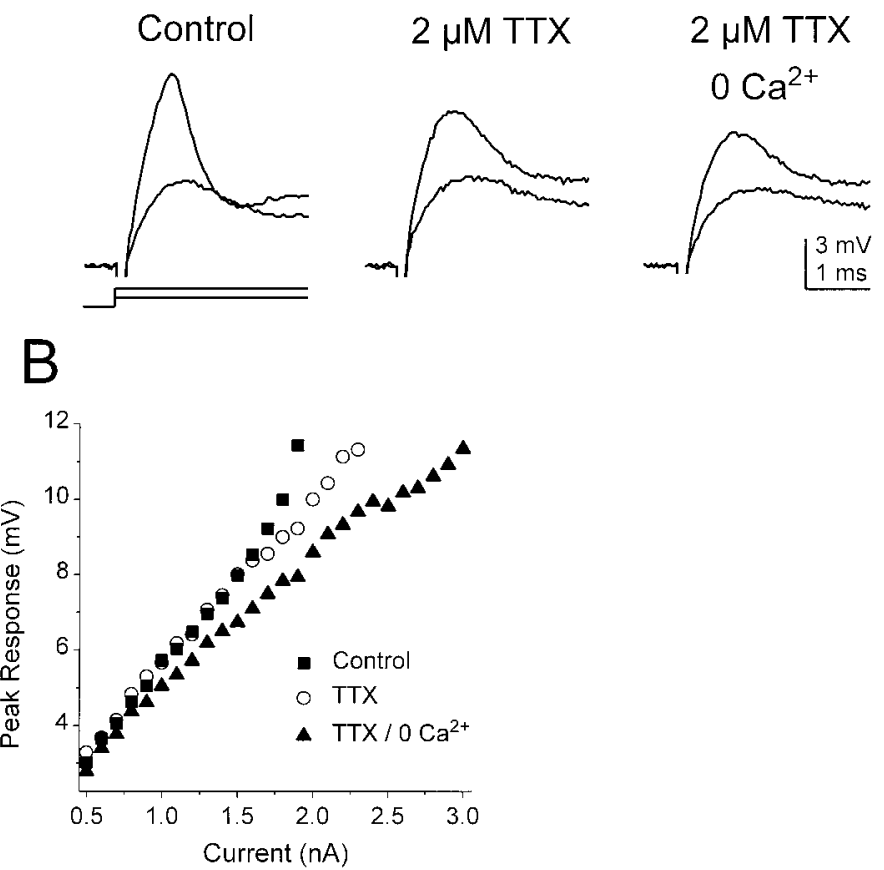

Figure 4. Amplification of subthreshold depolarizing responses by voltage-gated sodium and calcium channels. $A$, The initial response of an octopus cell to 0.9 and $1.9 \mathrm{nA}$ depolarizing current pulses shows a depolarizing transient (a "hump"). In the presence of TTX the initial transients were reduced by $\sim 2 \mathrm{mV}$, indicating that voltage-sensitive $\mathrm{Na}^{+}$ conductances had contributed to the transient response. Both larger and smaller responses were reduced further in a TTX $/ 0$ calcium solution, indicating an additional contribution from voltage-gated calcium channels. $B$, Amplitude of transient peak depolarizations versus stimulus current for the cell for which the traces are shown in $A$. Amplification of the initial voltage transient by sodium channels is apparent in responses $>8 \mathrm{mV}$ from rest, whereas amplification by calcium channels is apparent in responses $>5 \mathrm{mV}$ from rest. On elimination of the amplifying effects of sodium and calcium channels, an additional $1.1 \mathrm{nA}$ of current was required to depolarize the cell to a level that was just below the action potential threshold in control conditions. 
A
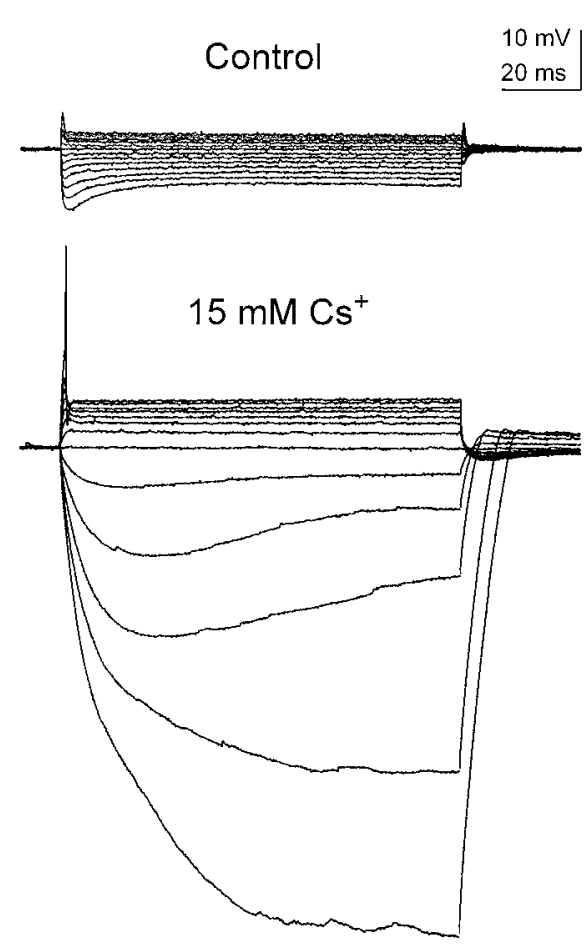

Wash

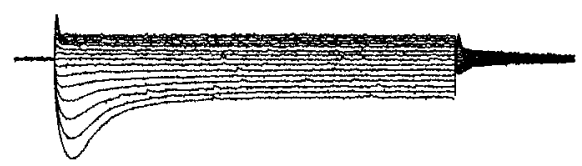

B

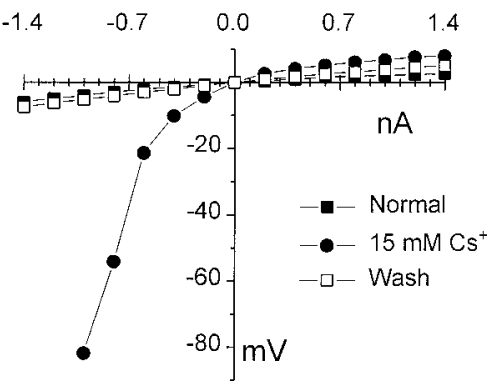

C
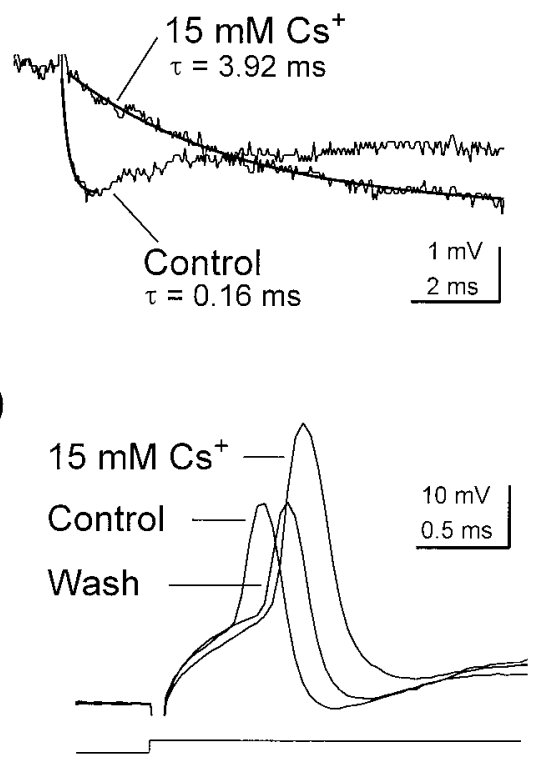

Figure 5. The effect of external cesium on the responses of an octopus cell to steps of injected current. $A$, External cesium (15 $\mathrm{mM}$ ) decreased the current required for action potential initiation, reduced the delayed depolarizing sag in responses to hyperpolarizing current steps, and increased the input resistance of the cell, particularly in the hyperpolarizing voltage range. Resting potentials (in $\mathrm{mV}$ ): Control, $-61 ; 15$ $m \mathrm{Cs}^{+},-66$; Wash, -63 . Current pulses: from 1.4 to $-1.4 \mathrm{nA}$ in $-0.2 \mathrm{nA}$ steps. $B$, The voltage-current relation derived from the traces in $A$. $C$, The membrane time constant of the cell in normal saline and 15 $\mathrm{mm}$ cesium. Hyperpolarizing responses of comparable magnitude in the two conditions were fit by single exponential functions (darker traces). The time constant increased by over an order of magnitude in the presence of external cesium. $D$, External cesium increased both the size and width of the action potential modestly and reversibly decreased the current necessary for their initiation from 2 to $1.6 \mathrm{nA}$. constant by over an order of magnitude (from $0.19 \pm 0.05$ to $2.98 \pm 1.10 \mathrm{msec} ; n=5$; Fig. $5 A-C$ ). Although the effects of cesium on input resistance and membrane time constant were less marked in the depolarizing voltage range, cesium nevertheless decreased the current necessary to reach threshold despite its hyperpolarizing the cell $(2.0 \pm 0.3 \mathrm{nA}$ in cesium vs $2.7 \pm 0.6 \mathrm{nA}$ in control; $n=4)$. Cesium also increased the average amplitude of action potentials by $63 \%$ and increased their average width by $37 \%$. These effects are attributable to the action of cesiumsensitive conductances on the formation of the action potential itself and/or a decrease in the attenuation of the action potential as it propagated to the recording site from its place of initiation (Fig. 5D).

The fact that inwardly rectifying cesium-sensitive conductances provide a tonic, depolarizing influence on the resting potential suggests that these conductances are not solely permeable to potassium, for which the equilibrium potential $\left(E_{\mathrm{k}}\right)$ resides in most neurons at approximately $-90 \mathrm{mV}$ (theoretical $E_{\mathrm{k}}=-94$ $\mathrm{mV}$ under the conditions of the present experiments). This hypothesis was examined more directly in experiments in which the extracellular concentration of sodium was reduced (substituted in equimolar concentrations with choline chloride) from 130 to 20 mм (Fig. $6 A-C ; n=3$ ). This manipulation hyperpolarized the resting potential by $6.5 \mathrm{mV}$ on average and reduced the delayed depolarizing sag in response to hyperpolarizing current steps, consistent with a shift in the reversal potential of the conductance toward the potassium equilibrium potential. This result strongly suggests that inward rectification in octopus cells is mediated extensively by a mixed cationic current $\left(I_{\mathrm{h}}\right)$ similar to that described in other neurons.

The high membrane conductance of octopus cells also was mediated by low-threshold voltage-gated potassium channels blocked by 4-AP. At a concentration of $5 \mathrm{~mm}, 4-\mathrm{AP}$ increased the input resistance of octopus cells near rest over sixfold, from $1.7 \pm$ 0.6 to $10.6 \pm 6.7 \mathrm{M} \Omega(n=5)$ and increased the membrane time constant by approximately an order of magnitude, from $0.21 \pm$ 0.06 to $2.22 \pm 0.38 \mathrm{msec}$ (Fig. $7 A-C ; n=5$ ). In contrast to the action of cesium, 4-AP markedly increased the input resistance in the depolarizing voltage range (Fig. $7 A, B$ ) and affected the generation and repolarization of action potentials. In the presence of 4-AP, action potentials broadened, and the current required for their initiation decreased without a significant change in membrane potential threshold (Fig. 7D). Similar effects were observed in parallel experiments that used $100 \mathrm{~nm} \alpha$-dendrotoxin (M. Ferragamo and D. Oertel, unpublished results). In two experiments the action potentials broadened by 4-AP were followed closely by larger, even wider spikes in response to currents at or only slightly above action potential threshold (Fig. 7D).

The pharmacology of these large, slow spikes was examined in experiments in which potassium channels were blocked nonspecifically by dialyzing the cell with a cesium-based internal solution, a manipulation that enabled these spikes to be elicited more 
Figure 6. Sodium dependence of inward rectification. $A$, Responses of an octopus cell to hyperpolarizing current steps of different magnitudes in normal physiological saline and saline in which extracellular sodium was reduced from 130 to $20 \mathrm{~mm}$. The reduction of extracellular sodium hyperpolarized the cell and reduced the sag toward rest. $B$, Steady-state voltage-current relationship of the same cell shows an increase in the input resistance over the hyperpolarizing voltage range. $C$, The difference between the steady-state and peak voltages (indicated in $A$ by arrows) in three different cells during the response to a $-4.0 \mathrm{nA}$ current step in normal and reduced extracellular sodium shows a statistically significant reduction in the mean sag in the presence of low extracellular sodium (Student's $t$ test; $p<0.05$; $n=3)$.
A

B

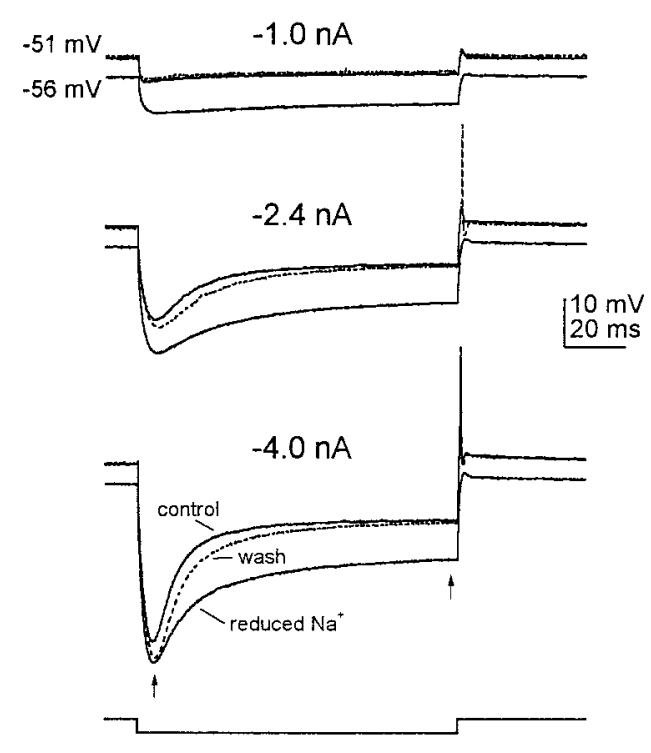

consistently. In experiments such as the one shown in Figure 8, trains of large, slow spikes elicited with current pulses (Fig. 8, top panel) could be eliminated when calcium was removed from the bathing medium (Fig. 8, middle panel), and this effect was completely reversible upon restoration of the physiological external calcium concentration (Fig. 8, bottom panel). Note also that the reduction of extracellular calcium attenuated the amplitude of the subthreshold transient at the onset of the responses, consistent with the finding that voltage-gated calcium channels amplify the onset of depolarizing voltage deflections (e.g., Fig. 4). These results indicate that octopus cells possess voltage-gated calcium channels that are capable of sustaining regenerative spiking when the influence of voltage-gated potassium channels, including those that are blocked by $4-\mathrm{AP}$, is reduced.

\section{DISCUSSION}

Octopus cells of the posteroventral cochlear nucleus have specialized properties that enable them to respond rapidly and precisely to synchronous excitatory synaptic input from the auditory nerve. Responses at the onset of rapid depolarizations are amplified by the action of sodium channels and, in some cells, calcium channels as well. This depolarizing influence is countered by the action of both outwardly rectifying potassium channels and inwardly rectifying mixed cationic channels for which the ranges of activation overlap in the physiological voltage range near rest. The combined action of potassium and mixed cationic channels contributes to a high resting membrane conductance, which in turn necessitates large inward currents to reach threshold for action potential initiation and suppresses repetitive firing.

\section{Inwardly rectifying conductances}

Octopus cells exhibit input resistances that are among the lowest recorded in any neuron in the brain. Several lines of evidence indicate that a contribution to the low resting input resistance of octopus cells comes from the activation of an inwardly rectifying current, denoted $I_{\mathrm{h}}$ (Gauss et al., 1998; Ludwig et al., 1998). Octopus cells, like other cells that possess $I_{\mathrm{h}}$, respond to hyperpolarizing current with a delayed depolarizing sag that is blocked by cesium. Channels mediating $I_{\mathrm{h}}$ are permeable to both potassium and sodium ions (Spain et al., 1987; McCormick and Pape, 1990; Fu et al., 1997); as a result, the reversal potential of $I_{\mathrm{h}}$ lies depolarized to rest, ranging between -25 and $-60 \mathrm{mV}$ (Banks et al., 1993; Mo and Davis, 1997b). Accordingly, in octopus cells both the resting potential and the degree of sag are sensitive to the extracellular concentration of sodium ions. Inward rectification mediated by $I_{\mathrm{h}}$ appears to be a consistent feature of auditory neurons at many levels in the auditory pathway (Oertel, 1983; Banks and Smith, 1992; Banks et al., 1993; Smith, 1995; Wu, 1996; Fu et al., 1997; Mo and Davis, 1997a). However, $I_{\mathrm{h}}$ appears to play a particularly prominent role in octopus cells because the conductance contributes substantially to the resting potential and resting conductance.

\section{Potassium conductances}

Octopus cells display strong outward rectification in response to depolarizing current. This outward rectification occurs at low threshold, lasts for the duration of the depolarizing stimulus, and is blocked by 4-AP and dendrotoxin. These properties are seen as a recurring motif among vertebrate auditory neurons concerned with maintaining timing information (for review, see Oertel, 1997; Trussell, 1997, 1999). Bushy cells of the cochlear nucleus were shown to respond rapidly in the physiological voltage range as a consequence of a rectifying conductance (Oertel, 1983; Wu and Oertel, 1984). The rectification in bushy cells was suggested to arise from the activation of a low-threshold, 4-AP-sensitive 


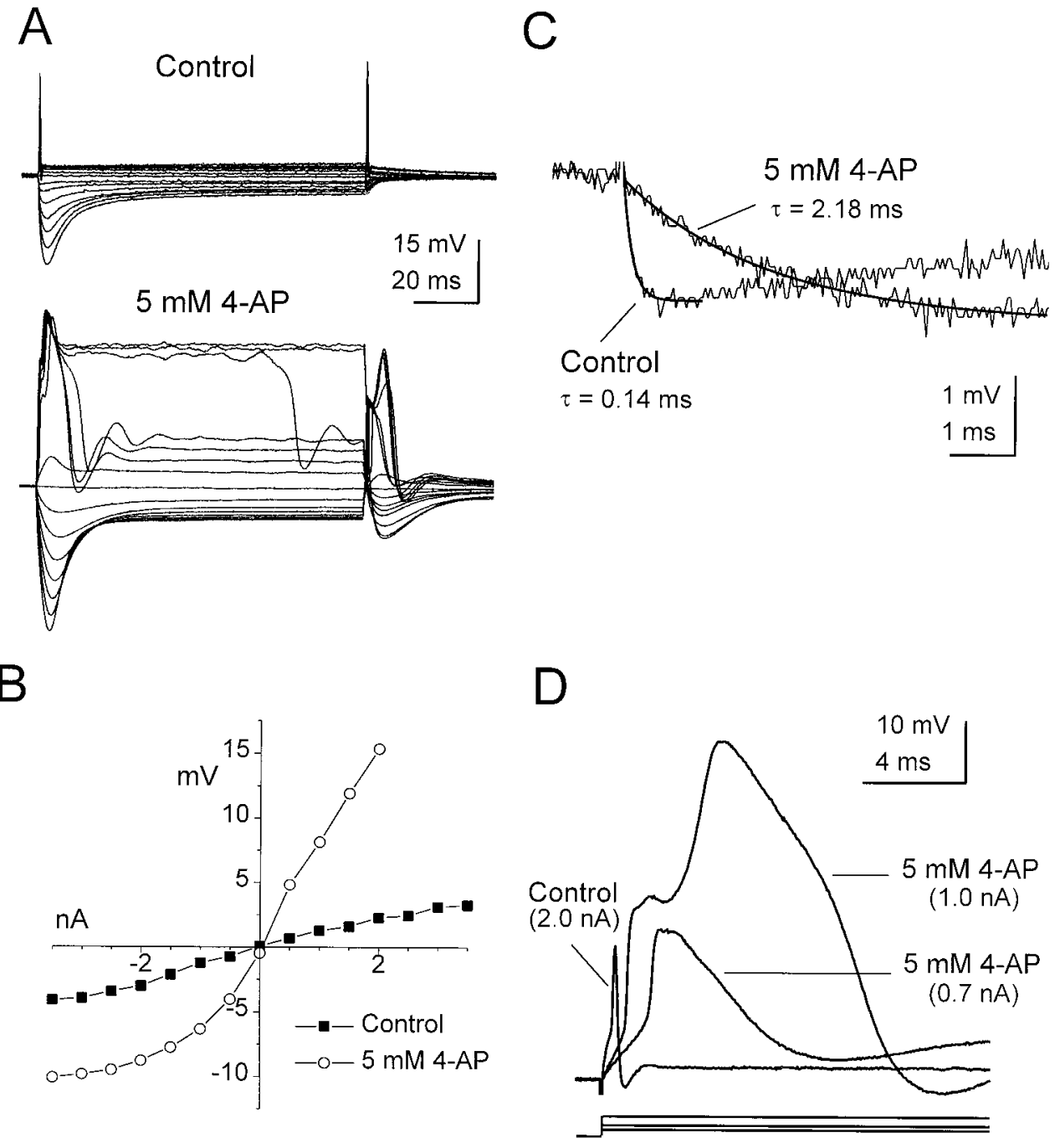

Figure 7. The influence of 4-AP on the responses of an octopus cell to steps of injected current. $A$, Responses of an octopus cell to current pulses between 3.5 and $-3.5 \mathrm{nA}$ in $-0.5 \mathrm{nA}$ steps. In the presence of 4-AP the input resistance of the cell increased over both the positive and negative voltage ranges, and complex spikes were elicited. $B$, The voltage-current relationship for the traces shown in $A$. Voltage measurements are the difference between the average membrane potential during the last $1 \mathrm{msec}$ of the response and the resting potential $(-60 \mathrm{mV}$ in control; $-59 \mathrm{mV}$ in 4-AP). $C$, The membrane time constant of the cell in the presence of 5 mM 4-AP increased by over an order of magnitude as compared with control (normal saline). $D$, The effect of 4 -AP on the initiation and shape of action potentials reveals two components. In the presence of 4-AP the action potential was broadened and was evoked with smaller injected currents. Larger injected currents in the presence of 4-AP evoked a second inflection and a second, larger spike. conductance (Manis and Marx, 1991). Similar conductances have been described in targets of bushy and octopus cells and their homologs in birds (for review, see Trussell, 1999). In several of these cells, those conductances also have been shown to be sensitive to dendrotoxin (Brew and Forsythe, 1995; Rathouz and Trussell, 1999; M. Ferragamo and D. Oertel, unpublished results). Both 4-AP and dendrotoxins block potassium channels of the Shaker (Kv1) family (Stühmer et al., 1989; Grissmer et al., 1994; Hopkins et al., 1994). Indeed, potassium channel $\alpha$-subunits Kv1.1, Kv1.2 (Wang et al., 1994), and Kv1.4 (Fonseca et al., 1998) have been shown to be expressed strongly in the octopus cell area as well as in other brainstem auditory nuclei.

\section{Amplification of depolarizing transients}

Depolarizing current induces a transient, depolarizing hump in octopus cells that is mediated by voltage-gated sodium channels and, in some cells, calcium channels as well. The $1-2 \mathrm{mV}$ contribution of these channels to depolarizing transients is a small, but nevertheless strong, influence on the excitability of the cell, constituting up to $20 \%$ of the necessary depolarization to reach threshold, a depolarization requiring up to $1 \mathrm{nA}$ of somatic current. The duration of subthreshold transients evoked by somatic current injection is $1-2 \mathrm{msec}$, a time course similar to that of EPSPs (Golding et al., 1995), making it likely that these currents amplify EPSPs.
How can the precise timing of EPSPs be maintained in the face of amplification by sodium and calcium conductances? In hippocampal and neocortical neurons the amplification of real and simulated EPSPs by sodium and low-threshold calcium conductances is associated with a prolongation of the depolarization (Stuart and Sakmann, 1995; Lipowsky et al., 1996; Gillessen and Alzheimer, 1997). By contrast, in octopus cells the amplification of depolarizing transients occurs with no increase in duration. This is likely to be the consequence of the strong secondary activation of potassium conductances. Thus, the intrinsic conductances of octopus cells appear to be finely tuned to deliver not only rapid onsets to excitation but rapid offsets as well.

\section{Action potential initiation and propagation}

The present results show that somatically injected currents of several nanoamps are required to reach action potential threshold in octopus cells, a finding that explains why action potentials were never observed to occur spontaneously and rarely were observed in responses to depolarizing current in a previous study that used sharp microelectrodes with limited current-passing capability (Golding et al., 1995). Action potentials in octopus cells are rapid and appear severely attenuated at the soma even when recorded with patch pipettes. Because action potentials are initiated typically near or in the first node of Ranvier of the axon (for review, see Johnston et al., 1996; Stuart et al., 1997), the small size of 


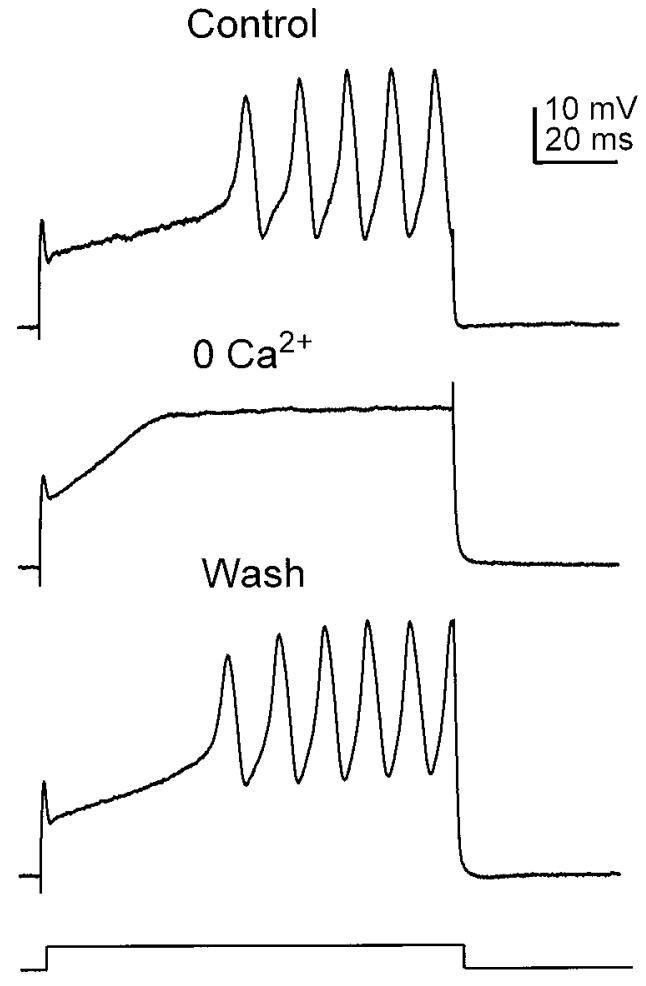

Figure 8. Calcium spikes evoked in the presence of internal cesium. In normal physiological saline the cell responded to a $3.4 \mathrm{nA}$ current pulse with a small depolarizing hump, followed by a train of larger, wider spikes. Removal of extracellular calcium reversibly eliminated the large spikes, revealing their calcium dependence. The removal of calcium from the bathing medium also reduced the amplitude of the small transient at the onset of the response, indicating that it was mediated in part by a calcium current.

backpropagating action potentials in octopus cells reflects the attenuation by potassium and mixed cationic conductances. However, the fact that action potential amplitude was increased only modestly when these shunting conductances were blocked pharmacologically (e.g., Figs. 5D, 7D) argues that the relative density of voltage-gated channels underlying the initiation of the action potential itself is unusual. Such specialization in the site of action potential initiation does not preclude normal conduction of the action potential in the axon itself. Regardless of the underlying mechanisms, the small size of backpropagating action potentials in octopus cells functionally reduces their distortion of the amplitude and timing of ongoing synaptic input, distortion that could degrade the encoding of the timing of synaptic excitation.

\section{Physiological implications}

The discovery that the spread of dendrites of octopus cells from the cell body to the tips of dendrites across the tonotopic array of auditory nerve fibers is consistently and without exception from low to high frequency (Oertel et al., 1990; Golding et al., 1995; this study) raises the possibility that the orientation of dendrites is of functional importance. Presumed octopus cells (cells with purely transient, so-called "Onset-i" responses) respond more strongly to sounds in which frequency is swept from low to high (Godfrey et al., 1975; Britt and Starr, 1976a,b; Rhode and Smith, 1986). These results indicate that action potentials are evoked most strongly when octopus cells are excited first by synaptic input near the soma. Whether the distinction in the direction of fre- quency sweeps is of biological importance as the recognition of an acoustic pattern is not known.

To fire action potentials, octopus cells require the summation of exceptionally brief EPSPs from many auditory nerve fibers (Golding et al., 1995). Yet why should there be a population of neurons that detects synchronous activity in the auditory nerve when activation of the cochlea by the traveling wave produces activity in the auditory nerve that is by nature asynchronous? The present observations suggest that the delay produced by the distortion of EPSPs of higher frequency input in the tips of dendrites might compensate for the traveling wave delay. In cats it takes 5-8 msec (Anderson et al., 1971; Ruggero and Rich, 1987) and in guinea pigs $\sim 2.6 \mathrm{msec}$ (Evans, 1972) for the traveling wave to spread from the oval window to the apex. In mice the traveling wave delay has not been measured; it is probably shorter, closer to the $\sim 1$ msec delay observed in bats (McCue, 1969), with individual octopus cells integrating input over only part of that range. The presence of $\mathrm{Ca}^{2+}, \mathrm{K}^{+}$, and $\mathrm{Na}^{+}$conductances in octopus cells demonstrated in the present experiments raises the further possibility that active conductances influence the spread of synaptic excitation that compensate for the traveling wave delay.

\section{REFERENCES}

Adams JC (1997) Projections from octopus cells of the posteroventral cochlear nucleus to the ventral nucleus of the lateral lemniscus in cat and human. Aud Neurosci 3:335-350.

Anderson DJ, Rose JE, Hind JE, Brugge JF (1971) Temporal position of discharges in single auditory nerve fibers within the cycle of a sine-wave stimulus: frequency and intensity effects. J Acoust Soc Am 49:1131-1139.

Banks MI, Smith PH (1992) Intracellular recordings from neurobiotinlabeled cells in brain slices of the rat medial nucleus of the trapezoid body. J Neurosci 12:2819-2837.

Banks MI, Pearce RA, Smith PH (1993) Hyperpolarization-activated cation current $\left(I_{\mathrm{h}}\right)$ in neurons of the medial nucleus of the trapezoid body: voltage-clamp analysis and enhancement by norepinephrine and cAMP suggest a modulatory mechanism in the auditory brainstem. J Neurophysiol 70:1420-1432.

Brew HM, Forsythe ID (1995) Two voltage-dependent $\mathrm{K}^{+}$conductances with complementary functions in postsynaptic integration at a central auditory synapse. J Neurosci 15:8011-8022.

Britt R, Starr A (1976) Synaptic events and discharge patterns of cochlear nucleus cells. II. Frequency-modulated tones. J Neurophysiol 39:179-194.

Cariani PA, Delgutte B (1996a) Neural correlates of the pitch of complex tones. I. Pitch and pitch salience. J Neurophysiol 76:1698-1716.

Cariani PA, Delgutte B (1996b) Neural correlates of the pitch of complex tones. II. Pitch shift, pitch ambiguity, phase invariance, pitch circularity, rate pitch, and the dominance region for pitch. J Neurophysiol 76:1717-1734.

Evans EF (1972) The frequency response and other properties of single fibres in the guinea-pig cochlear nerve. J Physiol (Lond) 226:263-287.

Feng J, Kuwada S, Ostapoff E-M, Batra R, Morest DK (1994) A physiological and structural study of neuron types in the cochlear nucleus. I. Intracellular responses to acoustic stimulation and current injection. J Comp Neurol 346:1-18.

Fonseca RC, Hallows JL, Trimmer JS, Rhodes KJ, Tempel BL (1998) Localization of Kv channels in the auditory system. Assoc Res Otolaryngol Abstr 21:213.

Friauf E, Ostwald J (1988) Divergent projections of physiologically characterized rat ventral cochlear nucleus neurons as shown by intra-axonal injection of horseradish peroxidase. Exp Brain Res 73:263-284.

Fu XW, Brezden BL, Wu SH (1997) Hyperpolarization-activated inward current in neurons of the rat's dorsal nucleus of the lateral lemniscus in vitro. J Neurophysiol 78:2235-2245.

Galambos R, Davis H (1943) The response of single auditory-nerve fibers to acoustic stimulation. J Neurophysiol 6:39-57.

Gauss R, Seifert R, Kaupp UB (1998) Molecular identification of a hyperpolarization-activated channel in sea urchin sperm. Nature 393:583-587. 
Gillessen T, Alzheimer C (1997) Amplification of EPSPs by low $\mathrm{Ni}^{2+}$ and amiloride-sensitive $\mathrm{Ca}^{2+}$ channels in apical dendrites of rat CA1 pyramidal neurons. J Neurophysiol 77:1639-1643.

Godfrey DA, Kiang NYS, Norris BE (1975) Single unit activity in the posteroventral cochlear nucleus of the cat. J Comp Neurol 162:247-268.

Golding NL, Robertson D, Oertel D (1995) Recordings from slices indicate that octopus cells of the cochlear nucleus detect coincident firing of auditory nerve fibers with temporal precision. J Neurosci 15:3138-3153.

Grissmer S, Nguyen AN, Aiyar J, Jayashree A, Douglas C, Mather RJ, Gutman GA, Karmilowicz MJ, Auperin DD, Chandy KG (1994) Pharmacological characterization of five cloned voltage-gated $\mathrm{K}^{+}$channels, types Kv1.1, 1.2, 1.3, 1.5, and 3.1, stably expressed in mammalian cell lines. Mol Pharmacol 45:1227-1234.

Hagiwara S, Miyazaki S, Rosenthal NP (1976) Potassium current and the effect of cesium on this current during anomalous rectification of the egg cell membrane of a starfish. J Gen Physiol 67:621-638.

Hopkins WF, Allen ML, Houamed KM, Tempel BL (1994) Properties of voltage-gated $\mathrm{K}^{+}$currents expressed in Xenopus oocytes by mKv1.1, mKv1.2, and their heteromultimers as revealed by mutagenesis of the dendrotoxin binding site in mKv1.1. Pflügers Arch 428:382-390.

Johnston D, Magee JC, Colbert CM, Cristie BR (1996) Active properties of neuronal dendrites. Annu Rev Neurosci 19:165-186.

Lipowsky R, Gillessen T, Alzheimer C (1996) Dendritic Na ${ }^{+}$channels amplify EPSPs in hippocampal CA1 pyramidal cells. J Neurophysiol 76:2181-2191.

Ludwig A, Zong X, Jeglitsch M, Hofmann F, Biel M (1998) A family of hyperpolarization-activated mammalian cation channels. Nature 393:587-591.

Manis PB, Marx SO (1991) Outward currents in isolated ventral cochlear nucleus neurons. J Neurosci 11:2865-2880.

McCormick DA, Pape HC (1990) Properties of a hyperpolarizationactivated cation current and its role in rhythmic oscillation in thalamic relay neurons. J Physiol (Lond) 431:291-318.

McCue JJG (1969) Signal processing by the bat, Myotis lucifugus. J Aud Res 9:100-107.

Mo Z-L, Davis RL (1997a) Endogenous firing patterns of murine spiral ganglion neurons. J Neurophysiol 77:1294-1305.

Mo ZL, Davis RL (1997b) Heterogeneous voltage dependence of inward rectifier currents in spiral ganglion neurons. J Neurophysiol 78:3019-3027.

Oertel D (1983) Synaptic responses and electrical properties of cells in brain slices of the mouse anteroventral cochlear nucleus. J Neurosci 3:2043-2053.

Oertel D (1997) Encoding of timing in the brain stem auditory nuclei of vertebrates. Neuron 19:959-962.

Oertel D (1999) The role of timing in the brainstem auditory nuclei of vertebrates. Annu Rev Physiol, in press.

Oertel D, Wu SH, Garb MW, Dizack C (1990) Morphology and physiology of cells in slice preparations of the posteroventral cochlear nucleus of mice. J Comp Neurol 295:136-154.

Rathouz M, Trussell LO (1999) A characterization of outward currents in neurons of the avian nucleus magnocellularis. J Neurophysiol 80:2824-2835.

Rhode WS (1994) Temporal coding of $200 \%$ amplitude modulated signals in the ventral cochlear nucleus of cat. Hear Res 77:43-68.

Rhode WS (1998) Neural encoding of single-formant stimuli in the ventral cochlear nucleus of the chinchilla. Hear Res 117:39-56.

Rhode WS, Smith PH (1986) Encoding timing and intensity in the ventral cochlear nucleus of the cat. J Neurophysiol 56:261-286.

Rhode WS, Oertel D, Smith PH (1983) Physiological response properties of cells labeled intracellularly with horseradish peroxidase in cat ventral cochlear nucleus. J Comp Neurol 213:448-463.
Rose JE, Brugge JF, Anderson DJ, Hind JE (1967) Phase-locked response to low-frequency tones in single auditory nerve fibers of the squirrel monkey. J Neurophysiol 30:769-793.

Ruggero MA, Rich NC (1987) Timing of spike initiation in cochlear afferents: dependence on site of innervation. J Neurophysiol 58:379-403.

Schofield BR (1995) Projections from the cochlear nucleus to the superior paraolivary nucleus in guinea pigs. J Comp Neurol 360:135-149.

Schofield BR, Cant NB (1997) Ventral nucleus of the lateral lemniscus in guinea pigs: cytoarchitecture and inputs from the cochlear nucleus. J Comp Neurol 379:363-385.

Smith PH (1995) Structural and functional differences distinguish principal from nonprincipal cells in the guinea pig MSO slice. J Neurophysiol 73:1653-1667.

Smith PH, Joris PX, Banks MI, Yin TCT (1993) Responses of cochlear nucleus cells and projections of their axons. In: The mammalian cochlear nuclei: organization and function (Merchan MA, Juiz JM, Godfrey DA, Mugnaini E, eds), pp 349-360. New York: Plenum.

Spain WJ, Schwindt PC, Crill WE (1987) Anomalous rectification in neurons from cat sensorimotor cortex in vitro. J Neurophysiol 57:1555-1576.

Stevens HE, Wickesberg RE (1999) Ensemble responses of the auditory nerve to normal and whispered stop consonants. Hear Res, in press.

Stuart GJ, Sakmann B (1995) Amplification of EPSPs by axosomatic sodium channels in neocortical pyramidal neurons. Neuron 15:1065-1076.

Stuart GJ, Spruston N, Sakmann B, Hausser M (1997) Action potential initiation and backpropagation in neurons of the mammalian CNS. Trends Neurosci 20:125-131.

Stühmer W, Ruppersberg JP, Schroter KH, Sakmann B, Stocker M, Giese KP, Perschke AB, Pongs O (1989) Molecular basis of functional diversity of voltage-gated potassium channels in mammalian brain. EMBO J 8:3235-3244.

Trussell LO (1997) Cellular mechanisms for preservation of timing in central auditory pathways. Curr Opin Neurobiol 7:487-492.

Trussell LO (1999) Synaptic mechanisms for coding timing in auditory neurons. Annu Rev Physiol, in press.

Vater M, Covey E, Casseday JH (1997) The columnar region of the ventral nucleus of the lateral lemniscus in the big brown bat (Eptesicus fuscus): synaptic arrangements and structural correlates of feedforward inhibitory function. Cell Tissue Res 289:223-233.

Voigt HF, Sachs MB, Young ED (1982) Representation of whispered vowels in discharge patterns of auditory-nerve fibers. Hear Res 8:49-58.

Wang H, Kunkel DD, Schwartzkroin PA, Tempel BL (1994) Localization of Kv1.1 and Kv1.2, two K channel proteins, to synaptic terminals, somata, and dendrites in the mouse brain. J Neurosci 14:4588-4599.

Wu SH (1996) Intrinsic membrane properties and firing characteristics of neurons in the ventral nucleus of the lateral lemniscus studied in rat brain slice. Soc Neurosci Abstr 22:647.

Wu SH, Oertel D (1984) Intracellular injection with horseradish peroxidase of physiologically characterized stellate and bushy cells in slices of mouse anteroventral cochlear nuclei. J Neurosci 4:1577-1588.

Wu SH, Oertel D (1987) Maturation of synapses and electrical properties of cells in the cochlear nuclei. Hear Res 30:99-110.

Yost WA, Patterson R, Sheft S (1996) A time domain description for the pitch strength of iterated rippled noise. J Acoust Soc Am 99:1066-1078.

Young ED, Sachs MB (1979) Representation of steady-state vowels in the temporal aspects of the discharge patterns of populations of auditory nerve fibers. J Acoust Soc Am 66:1381-1402. 